\title{
Conservação ambiental em zonas ripárias de dois córregos urbanos no município de Três Pontas, sul de Minas Gerais
}

\author{
Environmental conservation in riparian zones of two urban stream in the municipality of Três \\ Pontas, south of Minas Gerais
}

Conservación ambiental en riparia zonas de dos arroyos urbanos en el municipio de Três Pontas, sur de Minas Gerais

\author{
Renato Franklin de Miranda \\ ORCID: https://orcid.org/0000-0003-2924-8299 \\ Universidade Federal de Alfenas, Brasil \\ E-mail: renatofranklinbioq@gmail.com \\ Luciana Botezelli \\ ORCID: https://orcid.org/0000-0002-5916-0442 \\ Universidade Federal de Alfenas, Brasil \\ E-mail: luciana.botezelli@gmail.com \\ Paulo Augusto Zaitune Pamplin \\ ORCID: https://orcid.org/0000-0001-7318-9121 \\ Universidade Federal de Alfenas, Brasil \\ E-mail: paulo.pamplin@gmail.com
}

\begin{abstract}
Resumo
Definir as áreas de preservação permanente (APPs) urbanas, assim como conhecer a estrutura florística da vegetação ciliar e a qualidade ambiental dos córregos, são fatores fundamentais para o planejamento da expansão urbana. Diante desse contexto, esse artigo tem como objetivo avaliar o estado de conservação da zona ripária urbana dos córregos Araras e Formigas no município de Três Pontas, MG. A metodologia constituiu na aplicação de um Protocolo de Avaliação Rápida. Em geral, a maioria dos trechos analisados das zonas ripárias do córrego Araras apresentaram-se impactados, enquanto a maior parte dos trechos analisados do córrego Formigas apresentaram-se conservados. Os resultados demonstram a possibilidade de caracterização de um corpo d'água através de variáveis físicas e biológicas do habitat, bem como a facilidade de aplicação do método utilizado. A avaliação da integridade ambiental de qualquer ecossistema é o passo inicial para o planejamento e implantação de programas de manutenção, preservação e recuperação de ambientes e, portanto, uma ferramenta complementar que pode ser utilizada por órgãos gestores de recursos naturais e planejamento urbano.
\end{abstract}

Palavras-chave: Área de preservação permanente; Protocolo De Avaliação Rápida; Recursos hídricos.

\begin{abstract}
Defining urban permanent preservation areas (APPs), as well as knowing the floristic structure of the riparian vegetation and the environmental quality of the streams, are fundamental factors for planning urban expansion. Given this context, this article aims to assess the state of conservation of the urban riparian zone of the Araras and Formigas streams in the municipality of Três Pontas, MG. The methodology consisted in the application of a Rapid Assessment Protocol. In general, most of the analyzed stretches of the riparian zones of the Araras stream were impacted, while most of the analyzed stretches of the Formigas stream were preserved. The results demonstrate the possibility of characterizing a water body through physical and biological variables of the habitat, as well as the ease of application of the method used. The assessment of the environmental integrity of any ecosystem is the initial step for planning and implementing programs for the maintenance, preservation and restoration of environments and, therefore, a complementary tool that can be used by management agencies of natural resources and urban planning.
\end{abstract}

Keywords: Permanent preservation area; Rapid Assessment Protocol; Water resources.

\section{Resumen}

La definición de áreas urbanas de preservación permanente (APP), así como el conocimiento de la estructura florística de la vegetación de ribera y la calidad ambiental de los arroyos, son factores fundamentales para planificar la expansión urbana. En este contexto, este artículo tiene como objetivo evaluar el estado de conservación de la zona urbana ribereña de los arroyos Araras y Formigas en el municipio de Três Pontas, MG. La metodología consistió en la aplicación de un Protocolo de Evaluación Rápida. En general, la mayoría de los tramos analizados de las zonas ribereñas del arroyo Araras fueron impactados, mientras que la mayoría de los tramos analizados del arroyo Formigas 
se conservaron. Los resultados demuestran la posibilidad de caracterizar un cuerpo de agua a través de variables físicos y biológicos del hábitat, así como la facilidad de aplicación del método utilizado. La evaluación de la integridad ambiental de cualquier ecosistema es el paso inicial para planificar e implementar programas de mantenimiento, preservación y restauración de ambientes y, por lo tanto, una herramienta complementaria que puede ser utilizada por los organismos de gestión de los recursos naturales y la planificación urbana.

Palabras clave: Área de conservación permanente; Protocolo de Evaluación Rápida; Recursos hídricos.

\section{Introdução}

A modernização agrícola, a implementação da mecanização rural e de novas tecnologias, o aumento da migração das áreas rurais para as urbanas principalmente após a década de 1980 e os avanços tecnológicos da indústria e dos serviços são as principais mudanças na paisagem urbana, provocando um crescimento desordenado na taxa de ocupação dos centros urbanos, causando sérios danos ao meio ambiente (Buainain et al., 2014).

Segundo Castro et al. (2012), as matas ciliares influenciam em diversos parâmetros como na qualidade da água, na regulação do regime hídrico, na estabilização de margens do rio, na redução do assoreamento da calha do rio e são influenciadas pelas inundações, aporte de nutrientes e pelos ecossistemas aquáticos que elas margeiam.

Definir as áreas de preservação permanente (APPs) urbanas, assim como conhecer a estrutura florística da vegetação ciliar e a qualidade ambiental dos córregos, são fatores fundamentais para o planejamento da expansão urbana. Estas mesmas práticas são fundamentais para recomposição das matas ciliares, que são de extrema importância, pois também regularizam a vazão dos córregos e aporte de nutrientes, além de oferecer abrigo e alimento à fauna local (Lima, 1998).

Zonas ripárias são áreas que margeiam cursos hídricos e são consideradas áreas de preservação permanente (APPs) (Ribeiro e Walter, 2001). De acordo com Bowler et al. (2012), a presença de mata ciliar contribui para diminuição da temperatura dos corpos aquáticos, assim como o investimento na criação de zonas ribeirinhas arborizadas pode proporcionar benefícios em termos da mitigação de alguns dos efeitos ecológicos da mudança climática na temperatura da água.

Em relação ao aspecto hidrológico e ecológico, o sistema ripário contribui para a manutenção e resiliência dos córregos e sua vegetação devido a diversas interações ambientais, podendo aumentar a capacidade de armazenamento, manter a qualidade da água, estabilizar as margens e contribuir com equilíbrio térmico.

O crescimento urbano desordenado no entorno das zonas ripárias tem gerado muitos impactos negativos, como desmatamento, compactação do solo, poluição sonora causada pelo excesso de ruído, despejo de esgoto e resíduos sólidos, gerando contaminação do corpo hídrico e dos solos, além de gerar odores (Vogel et al., 2010).

Diante disso, é cada vez maior a necessidade de monitorar as mudanças ambientais e avaliar seu impacto nos ecossistemas fluviais. Como ferramenta de monitoramento desses ecossistemas, a avaliação ambiental fluvial fornece um importante subsídio para a análise abrangente de sua qualidade. Entre as ferramentas utilizadas para apoiar análise ambiental utilizadas em campo, podemos citar a aplicação do Protocolo de Avaliação Rápida (PAR), que se baseia em temas desenvolvidos para colaborar no monitoramento ambiental de sistemas hídricos, para que informações qualitativas possam ser obtidas por meio de um diagnóstico fácil de aplicar.

Os Protocolos de Avaliação Rápida (PARs), são utilizados qualitativa e semi-quantitativa, através de um conjunto de variáveis que representam os principais componentes físicos condicionantes e controladores dos processos e funções ecológicas de sistemas fluviais, e também sistematizam procedimentos de metodologia científica (Callisto et al., 2002; Rodrigues et al., 2008). Para Rodrigues et al. (2008), os PARs são instrumentos que adicionam indicadores de qualidade ambiental, referindo-se aos aspectos físicos e biológicos de um determinado ecossistema fluvial quando aplicado, podendo ser usados como uma ferramenta de avaliação dos recursos hídricos.

Os índices e protocolos são ferramentas essenciais para aplicar técnicas de avaliação e caracterizar diferentes tipos de impactos ambientais sobre água, florestas e meio ambiente. Após o término da etapa de classificação, com base nas respostas 
aos parâmetros analisados e através de uma observação qualitativa e quantitativa, conseguem determinar o estado de conservação do corpo d'água.

Através de um posicionamento quali-quantitativo, alguns estudos usam as expressões: péssimo, regular, bom e ótimo como respostas à aplicação de um índice, como mostra no estudo de Tanago et al. (2006), aplicando o Riparian Quality Index (RQI), que tem como enfoque as análises hidrológicas e geomorfológicas de áreas ripárias. Uma ferramenta de síntese rápida amplamente utilizada no Brasil é o Protocolo de Avaliação Rápida de Rios (PAR), conforme mostrado no trabalho de Vargas et al. (2012) e Rodrigues et al. (2012).

A técnica incorpora uma série de atribuições físicas, as quais são pontuadas ao longo de um gradiente numérico que gera nível de perturbação do curso d'água em análise, baseado na inspeção visual ou em quantidade mínima de medidas. A técnica visa a avaliação da estrutura e do funcionamento dos ecossistemas aquáticos presentes nas análises, contribui para o manejo e a conservação desses sistemas, através da aplicação de protocolos simplificados com parâmetros que facilitam o entendimento e a utilização (Callisto et al., 2002).

No município de Três Pontas - MG, ocorreu a ocupação desordenada no entorno da bacia hidrográfica do Ribeirão Araras. Devido à falta de planejamento adequado, atingiu diretamente os córregos e as zonas ripárias, ocasionando diversos impactos ambientais urbanos, como as enchentes frequentes na região que afetam diretamente a população (SAAE, 2009).

Diante do contexto apresentado, este trabalho tem como objetivo avaliar o estado de conservação da zona ripária de dois córregos urbanos, por meio de um Protocolo de Avaliação Rápida, adaptado para zona ripária do município de Três Pontas, MG. Assim, o fundamento de pesquisar esses parâmetros ambientais vem da necessidade de planejamento, recuperação, preservação e monitoramento das zonas ripárias dos córregos urbanos, e pela importância deste ambiente para a população, proporcionando uma zona de equilíbrio ecológico e bem-estar.

\section{Metodologia}

\subsection{Tipo de pesquisa e local de estudo}

Esta pesquisa é de natureza quali-quantitativa, quanto ao objetivo é definida como descritiva e, considerando-se o local, é uma pesquisa de campo (Souza et al., 2013).

Com o auxílio de imagens de satélites e atividades de campo, a pesquisa foi realizada nas zonas ripárias dos córregos Araras e Formigas, pertencentes a bacia hidrográfica do Ribeirão Araras, localizada na área urbana do Município de Três Pontas (latitude $21^{\circ} 22^{\prime} 16^{\prime \prime}$ Sul e longitude $42^{\circ} 30^{\prime} 42^{\prime \prime}$ Oeste), região sul do estado de Minas Gerais (Figura 1). 
Figura 1: Localização do Município de Três Pontas, região sul de Minas Gerais.

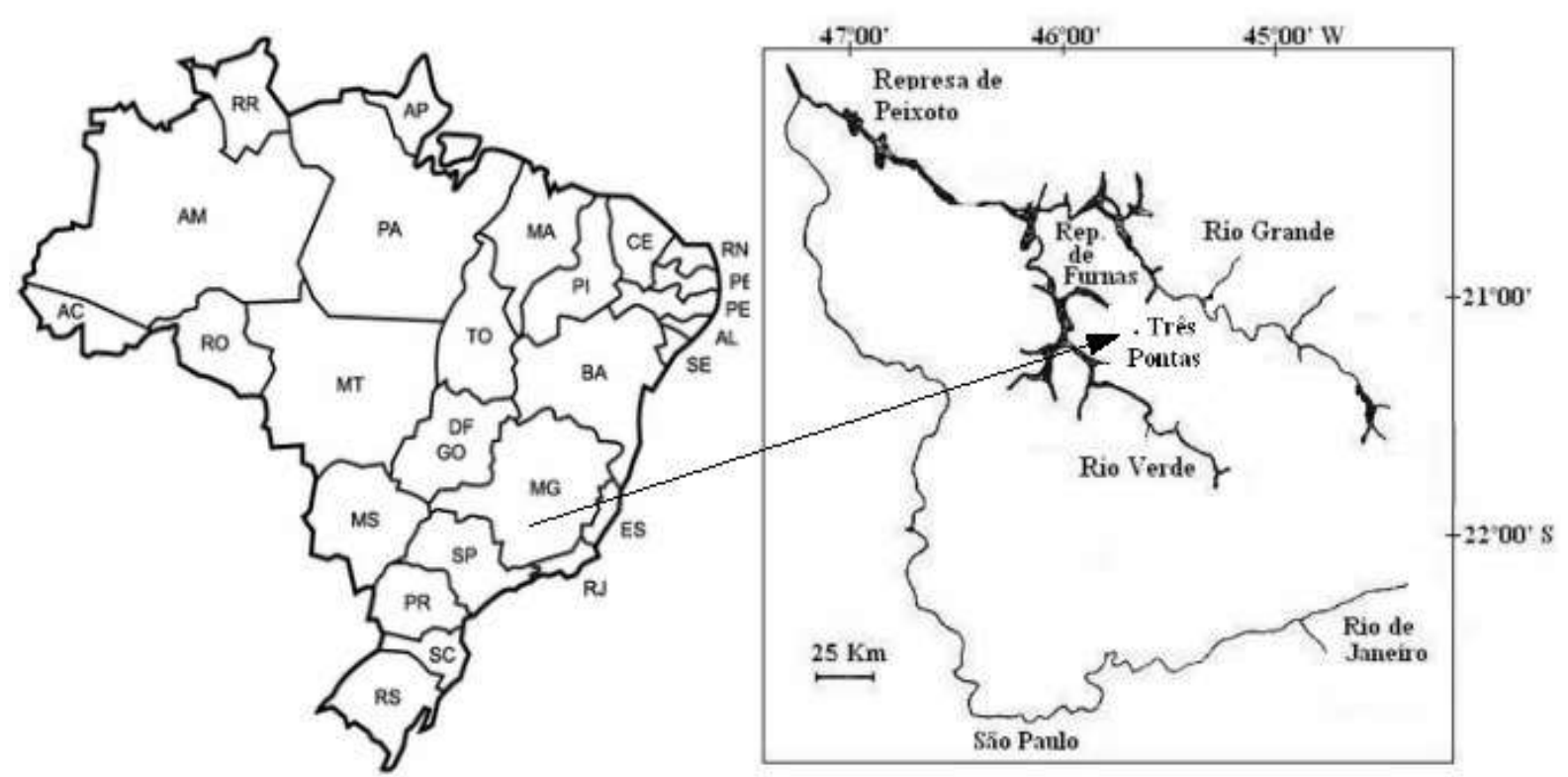

Fonte: Ferreira (2010).

A área urbana do município de Três Pontas é cortada por diversos ribeirões e córregos. Pode-se destacar o ribeirão das Araras, o córrego Custodinho, córrego Quatis, córrego Formigas, ressaltando que esses três córregos são mananciais de captação de água para consumo, e tem suas nascentes em zona rural. O córrego das Araras é o principal curso d'água da microbacia, recebendo o volume de água de todos os outros córregos pertencentes a área de drenagem, assim como o esgoto doméstico e industrial, sem nenhum tipo de tratamento. Já o córrego das Formigas é um dos afluentes da microbacia do Ribeirão Araras, sendo um dos mananciais de captação de água para abastecimento urbano.

Na Figura 2 tem-se os pontos de aplicação do Protocolo de Avaliação Rápida (PAR) em 10 (dez) trechos do córrego Araras (CA) e 10 (dez) trechos no córrego Formigas (CF).

Figura 2: Indicação dos trechos de aplicação do PAR nos córregos Araras e Formigas, Município de Três Pontas, MG.

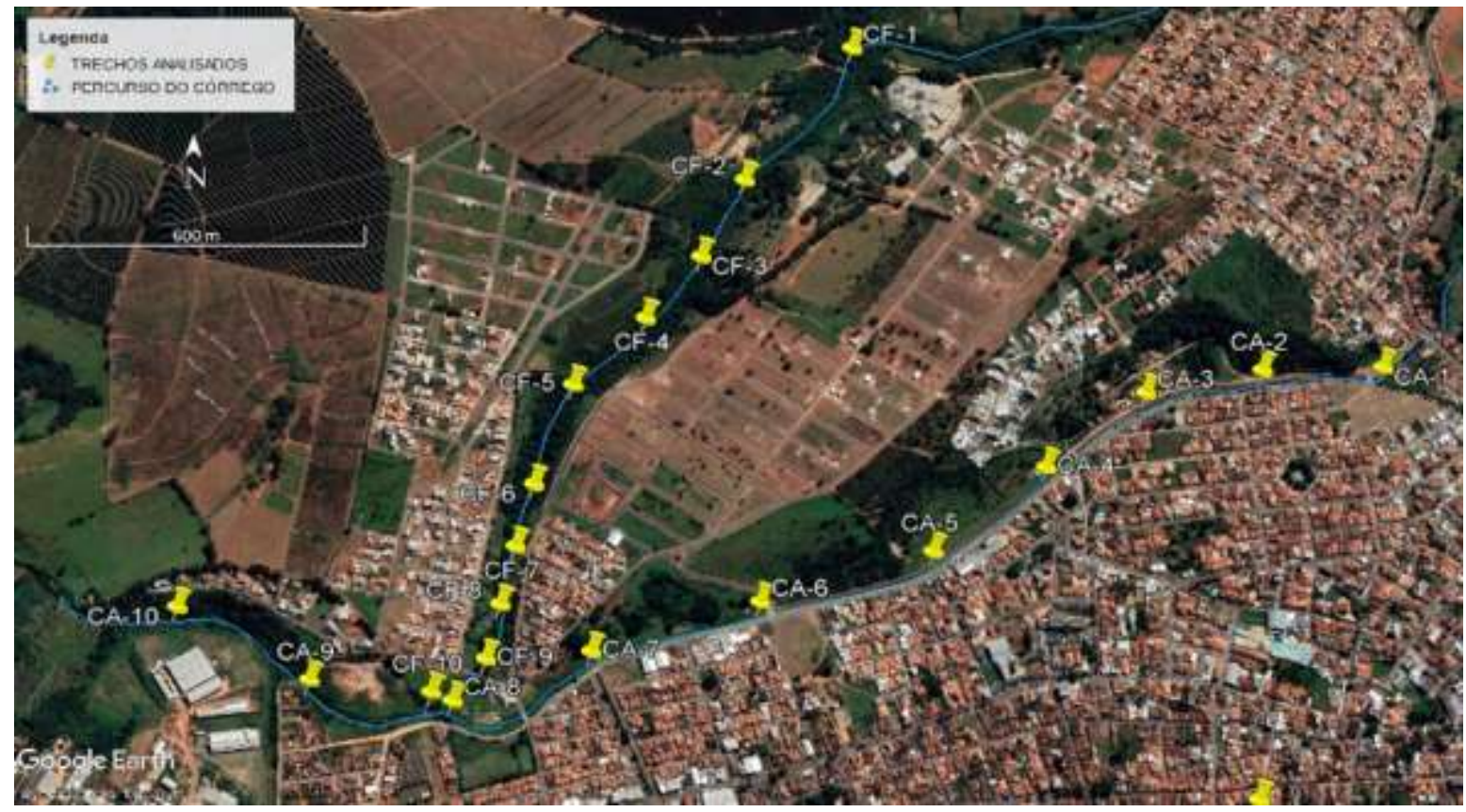

Fonte: Adaptado de Google Earth Pró (2021) pelos autores. 


\subsection{Protocolo de Avaliação Rápida}

Neste estudo optou-se pela utilização do PAR que já vem sendo utilizado no Brasil para realizar avaliação do estado de conservação da zona ripária de áreas de preservação permanente (APP). O PAR é um procedimento cientificamente válido e de baixo custo, capaz de gerar resultados rápidos para apoiar as decisões de gestão e auxiliar na produção de relatórios que podem ser compreendidos pela população em geral (Barbour et al., 1999). A análise constituiu na aplicação de um PAR em trechos de zona ripária nos córregos Araras e Formigas, aplicado no mês de junho e julho de 2021, em 10 pontos amostrais em cada córrego.

O PAR utilizado foi adaptado com base no estudo de Callisto et al. (2002) e em conceitos de ecologia de conservação. Para este estudo foi montada uma planilha contendo dez (10) variáveis indicadoras indicadores, sendo: tipo de ocupação das margens do corpo d'água (principal atividade), erosão próxima e/ou nas margens do rio e assoreamento em seu leito, alterações antrópicas, odor da água, depósitos sedimentares, presença de plantas aquáticas, descontinuidade da mata ciliar, largura da mata ciliar extraídos de Callisto et al. (2002), e presença de animais domésticos, presença de fogo, sugeridos com base na ecologia de conservação, sendo que todos parâmetros variaram entre $0,2,3$ e 5, conforme o verificador correspondente, podendo atingir um total de 50 pontos.

Após o resultado da aplicação do PAR, obteve-se um resultado com os seguintes níveis de classificação: 0 a 20 pontos representa trechos impactados, de 21 a 30 pontos representa trechos alterados e de 31 a 50 pontos representa trechos conservados, sendo esse considerado ponto "referência" a qual apresenta melhores aspectos ambientais do habitat, relacionados no protocolo (Quadro 1).

Para o preenchimento do PAR, atentou-se para as seguintes observações: para o indicador 1 considerou-se o verificador com a principal atividade ao longo do trecho; para o indicador 2 na existência de mais de um verificador, considerou-se o fator de degradação mais agressor; e para o indicador 7 quando houve mais de uma descontinuidade, levou em consideração o verificador mais agressivo para o indicador 8 recomendou-se mensurar a largura da vegetação em campo, e também através de softwares como o Google Earth Pro, ou similares, para calcular uma média real da largura dos fragmentos .

Quadro 1: Protocolo de Avaliação Rápida do Estado de Conservação de Rios.

\begin{tabular}{|c|c|c|c|c|}
\hline \multirow{2}{*}{ PARÂMETROS } & \multicolumn{3}{|c|}{ PONTUAÇÃo } \\
\cline { 2 - 5 } $\begin{array}{c}\text { 1. Tipo de ocupação } \\
\text { das margens do corpo } \\
\text { d'água (principal } \\
\text { atividade) }\end{array}$ & $\begin{array}{c}\mathbf{5} \text { pontos } \\
\text { Vegetação natural } \\
\text { em estágio médio } \\
\text { ou avançado de } \\
\text { sucessão ecológica. }\end{array}$ & $\begin{array}{c}\mathbf{3} \text { pontos } \\
\text { Reflorestamento } \\
\text { apresentando extrato } \\
\text { arbustivo-arbóreo }\end{array}$ & $\begin{array}{c}\text { 2 pontos } \\
\text { Campo de } \\
\text { pastagem/Agricultura/ } \\
\text { Monocultura/ Solo } \\
\text { exposto }\end{array}$ & $\begin{array}{c}\text { 0 pontos } \\
\text { Edificações de uso } \\
\text { Residencial/ Comercial/ } \\
\text { Industrial }\end{array}$ \\
\hline $\begin{array}{c}\text { 2. Erosão próxima } \\
\text { e/ou nas margens do } \\
\text { rio e assoreamento em } \\
\text { seu leito }\end{array}$ & Ausente & $\begin{array}{c}\text { Estabilizada } \\
\text { (controlada pela } \\
\text { vegetação) }\end{array}$ & $\begin{array}{c}\text { Moderada } \\
\text { (solapamentos } \\
\text { eventuais) }\end{array}$ & Acentuada (embaciamento) \\
\hline $\begin{array}{c}\text { 3. Alterações } \\
\text { antrópicas }\end{array}$ & Ausente & $\begin{array}{c}\text { Alterações de origem } \\
\text { doméstica de baixo } \\
\text { impacto (pontes, } \\
\text { poços de } \\
\text { abastecimento de } \\
\text { água). }\end{array}$ & $\begin{array}{c}\text { Lançamento de esgoto } \\
\text { doméstico, lixo } \\
\text { doméstico e presença } \\
\text { de canais de } \\
\text { drenagem. }\end{array}$ & $\begin{array}{c}\text { Alterações de origens } \\
\text { industrial (fabricas, } \\
\text { canalização retificação do } \\
\text { curso do rio ou afluente, } \\
\text { barramento, lançamento de } \\
\text { efluentes }\end{array}$ \\
\hline 4. Odor da água & Nenhum & $\begin{array}{c}\text { Presença de biomassa } \\
\text { animal ou vegetal em } \\
\text { decomposição na } \\
\text { lâmina d'água. }\end{array}$ & Esgoto (ovo podre) & $\begin{array}{c}\text { Óleo industrial (Ex.: } \\
\text { vinhaça, torta de filtro) }\end{array}$ \\
\hline
\end{tabular}




\begin{tabular}{|c|c|c|c|c|}
\hline $\begin{array}{l}\text { 5. Depósitos } \\
\text { sedimentares }\end{array}$ & $\begin{array}{l}\text { Depósitos aluviais } \\
\text { nas margens do rio } \\
\text { decorrente do } \\
\text { transporte natural } \\
\text { dos sedimentos ou } \\
\text { ausentes. } \\
\end{array}$ & $\begin{array}{l}\text { Depósitos aluviais } \\
\text { extravasando as } \\
\text { margens do rio sem } \\
\text { vestígio de } \\
\text { solapamento }\end{array}$ & $\begin{array}{l}\text { Depósito aluviais nas } \\
\text { margens do rio com } \\
\text { vestígio de } \\
\text { solapamento. }\end{array}$ & $\begin{array}{l}\text { Depósito aluviais no leito } \\
\text { do rio (assoreamento) }\end{array}$ \\
\hline $\begin{array}{l}\text { 6. Presença de animais } \\
\text { domésticos }\end{array}$ & Ausente & Presença esporádica & $\begin{array}{c}\text { Área para } \\
\text { dessedentação de } \\
\text { animais em APP }\end{array}$ & $\begin{array}{c}\text { Confinamento frequente de } \\
\text { animais em APP }\end{array}$ \\
\hline 7. Presença de fogo & Ausente & $\begin{array}{c}\text { Queimadas no } \\
\text { entorno da APP, mais } \\
\text { de } 30 \mathrm{~m} \text { da calha } \\
\text { d'água }\end{array}$ & $\begin{array}{l}\text { Queimadas para } \\
\text { controle de gramíneas } \\
\text { e pastagens em } \\
\text { período de seca }\end{array}$ & $\begin{array}{c}\text { Queimada continua nas } \\
\text { APPs. }\end{array}$ \\
\hline $\begin{array}{c}\text { 8. Presença de plantas } \\
\text { aquáticas }\end{array}$ & $\begin{array}{c}\text { Presença de } \\
\text { formação paludosa }\end{array}$ & $\begin{array}{l}\text { Pequenas macrófitas } \\
\text { aquáticas nativas e/ou } \\
\text { musgos distribuídos } \\
\text { pelo rio }\end{array}$ & $\begin{array}{c}\text { Ausência de } \\
\text { Vegetação aquática } \\
\text { nativas no leito do rio }\end{array}$ & $\begin{array}{c}\text { Presença de grandes bancos } \\
\text { de macrófitas exóticas (Ex.: } \\
\text { aguapé) }\end{array}$ \\
\hline $\begin{array}{l}\text { 9. Descontinuidade da } \\
\text { mata ciliar }\end{array}$ & Contínua & $\begin{array}{l}\text { Descontínua com a } \\
\text { matriz permeável } \\
\text { (bosques exóticos } \\
\text { e/ou cultivos } \\
\text { diversificados). }\end{array}$ & $\begin{array}{c}\text { Descontínua com a } \\
\text { matriz pouco } \\
\text { permeável } \\
\text { (monocultivos, } \\
\text { pastagens e solo } \\
\text { exposto). }\end{array}$ & $\begin{array}{l}\text { Descontínua com a matriz } \\
\text { impermeável (edificações). }\end{array}$ \\
\hline $\begin{array}{l}\text { 10. Largura da mata } \\
\text { ciliar }\end{array}$ & $\begin{array}{l}\text { Largura da } \\
\text { vegetação ripária } \\
\text { maior que } 30 \mathrm{~m} ; \\
\text { sem influência de } \\
\text { interferência } \\
\text { antrópicas } \\
\text { (agropecuária, } \\
\text { estradas, etc) }\end{array}$ & $\begin{array}{l}\text { Largura da vegetação } \\
\text { ripária entre } 20 \text { e } \\
30 \mathrm{~m} \text {; mínima } \\
\text { influência antrópica. }\end{array}$ & $\begin{array}{c}\text { Largura da vegetação } \\
\text { ripária entre } 10 \text { e } 20 \mathrm{~m} \text {; } \\
\text { influência antrópica } \\
\text { intensa. }\end{array}$ & $\begin{array}{l}\text { Largura da vegetação } \\
\text { ripária menor que } 10 \mathrm{~m} ; \\
\text { vegetação restrita ou } \\
\text { ausente devido à atividade } \\
\text { antrópica. }\end{array}$ \\
\hline
\end{tabular}

Fonte: Adaptado de Callisto et al. (2002).

\section{Resultados e Discussão}

\subsection{Conservação ambiental do córrego Araras}

Os dados revelaram cenários diferentes entre os dois córregos. No córrego Araras, verificou-se uma maior alteração das condições ambientais (Figura 3), sobre a zona ripária e curso hídrico, embora o lado esquerdo sentido à jusante apresentouse mais alterado que o lado direito. Localizado na área central do município de Três Pontas-MG, observou-se nos trechos do lado direito que toda a mata ciliar nativa foi retirada e, além disso, era visível o lançamento de esgoto doméstico por inúmeras tubulações que fazem seus despejos diretamente ao longo dos trechos avaliados, sem qualquer tipo de tratamento.

As análises mostraram pouca variação no estado de conservação dos trechos avaliados com exceção do trecho CA-10 que apesar da nítida presença de esgoto apresentando água acinzentada e com odor, possui as matas ciliares do lado direito sentido a jusante. A margem esquerda, apresenta grau de regeneração inicial, área permeável e passível de recomposição vegetal. Desta forma, o trecho CA-10 atingiu uma maior pontuação chegando em 27 pontos, sendo considerado um trecho com estado de conservação alterado. Os parâmetros que contribuíram para esse resultado foram presença de efluentes domésticos e pluviais, ausência de vegetação ciliar, processos erosivos, presença de animais domésticos e a retificação do curso do rio. 
Figura 3: Estado de conservação das zonas ripárias do córrego Araras, em Três Pontas, sul de Minas Gerais. Barra de cor vermelha representa trecho impactado, barra de cor amarela indica trecho alterado.

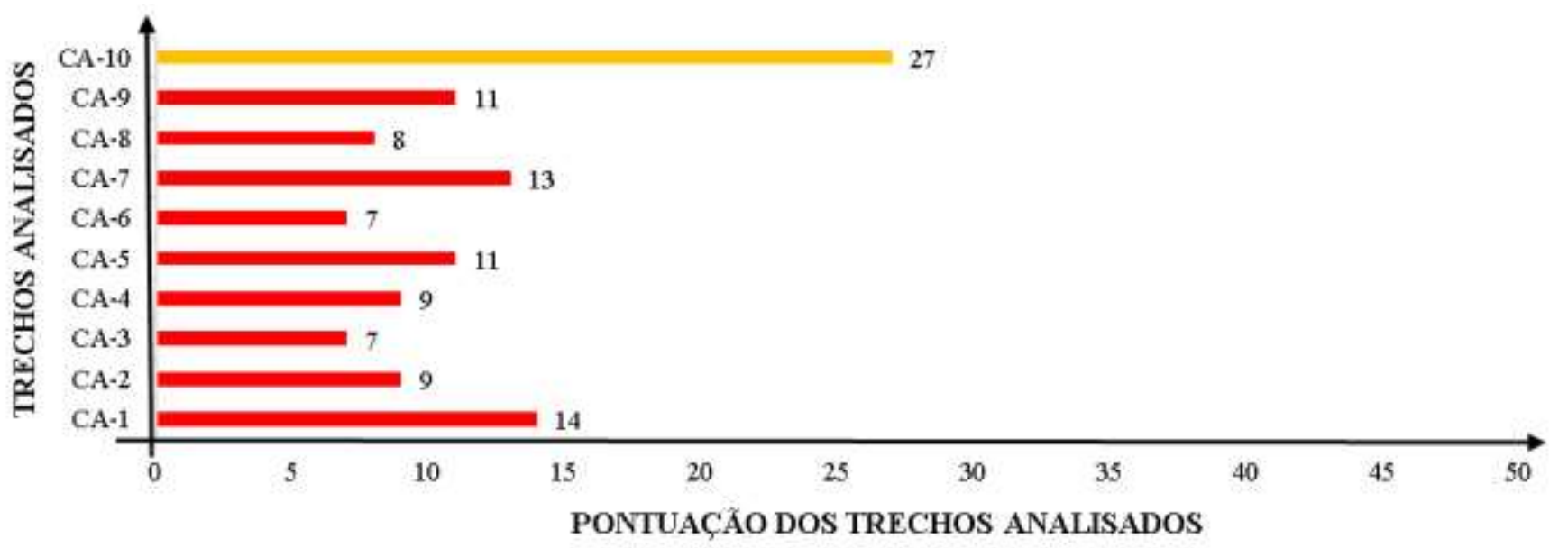

Fonte: Autores (2021).

Os trechos CA-1 a CA-9 acompanham a avenida Oswaldo Cruz do lado esquerdo, com a infraestrutura viária menos de 2 metros da calha do córrego, até onde se encontra a jusante do córrego do Candongas. Esta via foi impermeabilizada com a estrutura asfáltica em áreas de zona ripária substituindo a mata ciliar do córrego Araras. Do lado direito do córrego encontra se um fragmento de floresta preservado em estágio aparentemente avançado de regeneração, porém este fragmento esta interrompido por uma via secundária, que poderia ser retirada pois não afetaria a população no entorno sendo uma via de baixa utilidade.

Os trechos CA-1 a CA-9 variaram sua pontuação entre 7 e 14 pontos, demostrando pior estado de conservação ambiental, sendo considerados criticamente impactados. A avaliação ambiental desses trechos apontou que os parâmetros que mais contribuíram para este resultado foram: solo exposto, erosão, esgoto, assoreamento, depósito de aluviais, presença de animais domesticados, vestígio de queimadas, ausência de mata ciliar e resíduos de construção civil e doméstico.

No trecho CA- 7, encontra-se a junção dos córregos Candongas e Araras, onde há uma ponte interrompendo a APP, que se encontra totalmente desprotegida de mata ciliar. Neste ponto há grande presença de sedimentos assoreando o rio, o que causa uma barreira para o fluxo natural da água em períodos de chuvas fortes, acarretando em enchentes nas partes mais acima destes trechos.

Conforme Rodrigues et al. (2008) observou em sua avaliação, é notável que a ocupação urbana gera alterações drásticas nas condições ambientais nas zonas ripárias e nos sistemas fluviais e que as condições verificadas nos trechos CA-1 ao CA-9 demonstram isso. De acordo com Tucci (2002), vários conflitos e problemas têm sido gerados, devido à concentração e crescimento urbano desordenado, tais como a degradação ambiental dos mananciais, o aumento do risco das áreas de abastecimento com a poluição orgânica e química, a contaminação dos rios por esgotos doméstico, industrial e pluvial, enchente urbana gerada pela imprópria ocupação do espaço, pelo gerenciamento inadequado da drenagem urbana e a falta de coleta e disposição adequada do lixo urbano.

\subsection{Conservação ambiental do córrego Formigas}

O córrego Formigas é um dos afluentes da bacia hidrográfica do Ribeirão Araras, sendo suas nascentes em zona rural, e seu ponto de captação para abastecimento populacional encontra-se entre loteamentos, localizados em área de expansão 
urbana. O córrego Formigas apresentou um estado melhor de conservação ambiental quando comparado ao córrego Araras (Figura 4).

Figura 4: Estado de conservação das zonas ripárias do córrego Formigas em Três Pontas, sul de Minas Gerais. Barra de cor vermelha representa trecho impactado, barra de cor amarela indica trecho alterado e barra de cor verde indica trecho conservado.

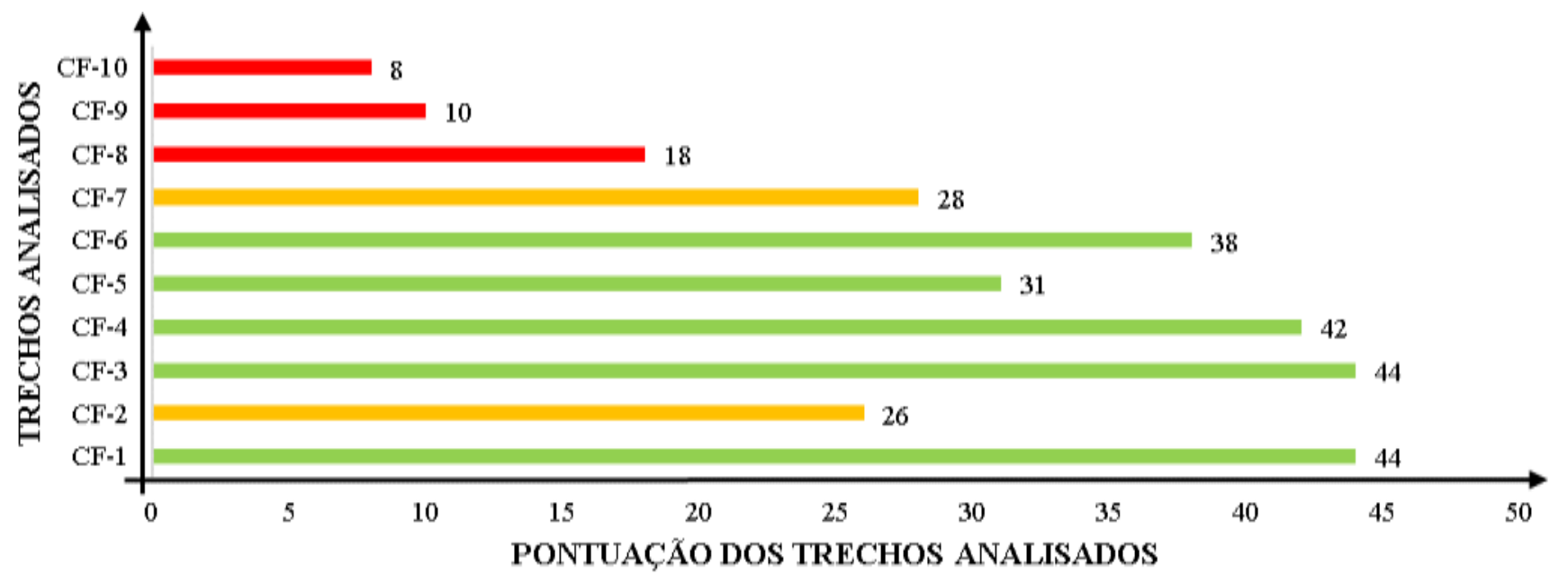

Fonte: Autores (2021).

As avaliações mostraram variação no estado de conservação dos trechos avaliados pelo PAR. Sendo que parte dessas decorrem de atividades econômicas presentes em trechos da zona ripária. Com os resultados das análises do PAR evidenciouse que a erosão do talude, descontinuidade horizontal e a largura da mata ciliar foram capitaneadas pelas atividades agropecuária e industrial, enquanto a constatação de odores de efluentes foram especialmente influenciados pela presença de esgoto in natura. Ambas as atividades contribuíram de forma negativa na avaliação de alguns trechos.

Os trechos CF-1, CF-3, CF-4, CF-5 e CF-6 apresentaram-se conservados, não sendo constatada nenhuma modificação nas características naturais. A mata ciliar encontra-se preservada e com a largura dentro dos padrões legais exigida pelo Código Florestal (Brasil, 2012). Foi possível observar rica diversidade vegetal com exemplares de óleo-de-copaíba (Copaifera langsdorffii), pau-terra (Qualea parviflora), pequi (Caryocar brasiliense), jatobá (Hymenaea courbaril), entre outras.

Percorrendo trechos, foi possível observar grande diversidade de aves como tucano-do-bico-vermelho (Ramphastos toco), sanhaçu-cinzento (Tangara sayaca), saíra-amarela (Tangara cayana), canário-da-terra (Sicalis flaveola), bem-te-vi (Pitangus sulphuratus), jacú (Penelope sp.), gavião-carijó (Rupornis magnirostris), gavião-carcará (Caracara plancus), entre outros, além de alguns grupos de primatas como mico-estrela (Callithrix penicillata) e cardumes de peixes.

A relação entre florestas ripárias/APPs urbanas e a avifauna é relatada em diferentes estudos e levantamentos como nos trabalhos de Almeida \& Cândido Junior 2007), Peña et al. (2010), Oliveira \& Blamires (2013). Esse ecossistema é de suma importância para a preservação e conservação de várias espécies faunística, florística e qualidade do recurso hídrico, contribuindo assim, com a qualidade de vida da população local.

Os trechos CF-2 e CF-7 encontram-se em estado de conservação ambiental alterados, o T2 atingiu o total de 27 pontos, onde encontrou-se uma indústria de lajes e blocos, e sítio com criação de gado na APP. Os parâmetros que contribuíram para esse resultado foram a descontinuidade nas matas ciliares, depósito de sedimentos nas margens, presença de gado para dessedentação. O trecho CF-7 atingiu um total de 28 pontos, onde encontrou-se cultivos de mandioca e milho dentro 
da APP. Os parâmetros que apresentaram piores condições ambientais foram: tipo de ocupação das margens, erosão próxima às margens, lixo doméstico e resto de construção civil, largura da vegetação ciliar inferior ao exigido por lei, podendo afetar a qualidade do recurso hídrico por assoreamento do leito do córrego.

Os trechos CF-8, CF-9 e CF-10 encontram-se em estado de conservação impactados, onde o T8 atingiu um total de 18 pontos, possui uma barragem de captação de água para consumo da população. Os parâmetros que apresentaram piores condições ambientais foram a mata ciliar descontínua, largura mínima exigida por lei, sistema de captação, presença de fogo e resíduos de construção civil e doméstico no entorno da vegetação ripária. Já o trecho CF-9 e CF-10 encontram-se totalmente desprotegidos de matas ciliares, atingindo um total de pontuação pouco variado, sendo, o trecho CF-9 com total de 10 pontos, e o trecho CF-10 com um total de 8 pontos, evidenciando um estado criticamente impactado. Os parâmetros que apresentaram piores condições ambientais foram processos erosivos dos taludes, presença de cavalos, ausência da vegetação ciliar, presença de fogo, tubulação de efluentes de origem doméstica e pluvial, água cinzenta e com odores.

Nos trechos analisados do córrego Formigas, apesar deste se encontrar em um estado de conservação superior ao córrego Araras, observou-se presença acentuada de resíduos sólidos provenientes de resto de construção civil no entorno da APP, interferindo na qualidade ambiental das zonas ripárias. Uma medida cabível para possível solução deste problema relacionada à disposição de resíduos sólidos doméstico e de construção civil nas zonas ripárias, seriam projetos de educação ambiental com a população local e com o setor de construção civil, além de leis específicas e fiscalização efetiva.

Estes dados são importantes, uma vez que são constatadas condições ambientais preservadas na zona ripária do córrego Formigas, localizado em uma área de transição entre a Mata Atlântica e o Cerrado. Além disto, demonstram que a preservação e recuperação destas APPs contribui com a preservação da qualidade ambiental dos recursos naturais disponíveis.

\subsection{Importância da manutenção da qualidade ambiental}

As mudanças recentes na composição das cidades brasileiras apontam para um conjunto de problemas e consequências ambientais comuns entre os municípios, destacando-se as questões relacionadas ao uso e ocupação da terra, à mobilidade urbana e ao saneamento ambiental, que acabam tendo maior potencialização pela rápida urbanização. Um modelo adotado no interior do Estado de São Paulo, apontou perdas e impactos no meio ambiente sem precedentes, como destruição de nascentes, assoreamento dos corpos d'água, erosão, maior vulnerabilidade a regiões de recarga do aquífero, alagamentos, inundações, aumento de temperatura, ocasionada pelo crescimento da área impermeabilizada, e supressão da vegetação nativa (Stanganini \& Lollo, 2018).

Segundo estudos de Lima et al. (2020), analisando os parâmetros da qualidade da água e os índices de qualidade ambiental (IQA) dos canais da bacia hidrográfica do Una no município de Belém, mostraram os impactos sofridos provenientes de disposição inadequada de resíduos sólidos, lançamento de efluentes sem tratamento, criação de animais e construção de áreas de lazer, propiciado a degradação da qualidade da água da sub-bacia.

Programas de incentivo a arborização nas áreas urbanas é de suma importância para minimizar a temperatura local. Estudo realizado por Barboza et al. (2020), apontaram que o processo acentuado de urbanização contribuiu para alterar as condições microclimáticas da cidade de Juazeiro do Norte, visto que houve uma diferença significativa na temperatura, umidade relativa do ar e velocidade dos ventos nas regiões estudadas. A arborização é fundamental para amenizar os efeitos negativos da urbanização e melhoria das variáveis microclimáticas.

Sousa et al. (2021) afirmaram que houve diminuição na qualidade da água do riacho Cacau, no Portal da Amazônia em Imperatriz, MA, no decorrer dos anos 2015 a 2019, tanto no período de chuva quanto no período de seca, ligando esse comportamento diretamente às mudanças causadas pelo crescimento imobiliário influenciando de forma direta a diminuição 
nos índices de qualidade de água, portanto causando uma maior contaminação por meio de maiores cargas de poluentes e contaminantes presentes nos efluentes domésticos e sanitários.

A degradação ambiental em perímetros urbanos e também rurais, demostram a relevância de metodologias de recuperação ambiental emergenciais, pois tratam de fontes de conservação de espécies endêmicas destes ambientes que possuem fragilidade ambiental elevada, principalmente devido a escoamento superficial de solo, crescimento urbano, supressão vegetal em áreas urbanas canalização de cursos hídricos, entre outros danos causados por ações antrópicas a áreas de nascentes (Matos et al., 2020). Os mesmos autores evidenciam a importância do pagamento por serviço ambiental como uma ferramenta para o desenvolvimento ambiental de maneira sustentável e não penalizada, ou seja, de maneira educativa e voluntária, trazendo benefícios sociais e ambientais para a população.

\section{Conclusão}

Identificou-se, através da aplicação do PAR apresentado, os principais fatores intervenientes na qualidade ambiental das zonas ripárias dos trechos dos córregos urbanos analisados. No córrego Araras há uma provável contaminação por lançamento de efluentes de esgoto doméstico, que vem prejudicando a qualidade do corpo hídrico. De outro modo, constatouse que a atividade agropecuária nas zonas ripárias tem provocado acentuada erosão das margens, ocasionando perda de solo e da vegetação associada e, consequentemente, o desequilíbrio ambiental do ecossistema ripário.

Diante disto, fica evidente a importância do incentivo à preservação e conservação de remanescentes florestais nas áreas de zona ripária e corpos de água em especial no córrego da Formiga, o qual pode ser valioso como área referência em futuros estudos de monitoramento ambiental através da metodologia utilizada neste trabalho.

Para tanto, vale ressaltar que o PAR aqui utilizado é instrumento complementar às abordagens convencionais de avaliação da qualidade ambiental da zona ripária. Uma avaliação mais apurada da conservação ambiental de um determinado curso de água deve incluir estudos de análise físico-química e bacteriológica da água, bem como levantamento da diversidade da flora e fauna, com o objetivo de se obter uma visão mais complexa e integrada do funcionamento e dos possíveis problemas aos quais encontra-se sujeito o ambiente de zonas ripárias urbanas. A avaliação da integridade ambiental de qualquer ecossistema é o passo inicial para o planejamento e implantação de programas de manutenção, preservação e recuperação de ambientes e, portanto, uma ferramenta complementar que pode ser utilizada por órgãos que tratem do planejamento ambiental urbano. Recomenda-se, ainda, a realização destes estudos em outros córregos que cortam a área urbana em questão, assim como a replicação em outros municípios.

\section{Referências}

Almeida, A. C. \& Cândido Júnior, J. F. (2017). A importância de parques urbanos para a conservação de aves. Arquivos de Ciências Veterinárias e Zoologia da UNIPAR, 20(4), 189-199.

Barbour, M. T. et al. (1999). Rapid bioassessment protocols for use in streams and wade able rivers: periphyton, benthic macroinvertebrates and fish. (2a ed.), EPA.

Barboza, E. N., Alencar, G. S. da S. \& Alencar, F. H. H. de. (2020). Arborização melhora o conforto térmico em áreas urbanas: O caso de Juazeiro do Norte, Ceará. Research, Society and Development, 9 (6), e105963691. https://doi.org/10.33448/rsd-v9i6.3691

Brasil. (2012). Lei $n^{o}$ 12.651, 25 de maio de 2012. Dispõe sobre a proteção da vegetação nativa e dá outras providências. Diário Oficial da República Federativa do Brasil, Brasília, DF.

Bowler, D. E., Mant, R., Orr, H., Hannah, D. M. \& Pullin, A. S. (2012). What are the effects of wooded riparian zones on stre am temperature? Environmental ZEvidence, 1(3), 1- 9. http://dx.doi.ore/10.1186/2047-2382-1-3

uainain, A. M., Alves, E., Silveira, J. M. da, Navarro, Z. \& Buainain, A. M. (2014). Transformação histórica e padrões tecnológicos da agricultura brasileira. In: O mundo rural no Brasil do século 21: a formação de um novo padrão agrário e agrícola. Brasília: Embrapa, p. 395-421, 2014b.

Callisto, M. et al. (2002). Aplicação de um protocolo der avaliação rápida de diversidade de habitats em atividades de ensino e pesquisa (MG, RJ). Acta Limnologica Brasiliensis, 14(1), 91-98. 
Callisto, M., Moreno, P. \& Barbosa, F. A. R. (2001). Habitat diversity and benthic functional trophic groups Serra do Cipó, Southeast Brazil. Rev. Bras. Biol., 61(2), 259-266.

Castro, D., Mello, R. S. P. \& Poester, G. C. (2012). Práticas para restauração da mata ciliar. Catarse.

Ferreira, C. S. 2010. Diversidade e análise faunística de crisopídeos (Neuroptera: Chrysopidae) em fragmento de floresta estacional semidecidual em Três Pontas, Minas Gerais. xi, 87 f. Tese (doutorado) - Universidade Estadual Paulista, Faculdade de Ciências Agrárias e Veterinárias. http://hdl.handle.net/11449/102300.

Guimarães, M. M. A. (2020). Influência da arborização urbana e do ruído sobre a avifauna do Plano Piloto de Brasília. Dissertação (Mestrado em Ciências Ambientais), Universidade de Brasília, Brasília-DF.

Lima, A.C. de M., Fernandes, L.L., Lopes, D.F., Bittencourt, G.M., Vinagre, M.V. de A. \& Silva, E.M. da. (2020). Urbanização e canais urbanos: avaliação da qualidade da água da bacia hidrográfica do Una na cidade de Belém, Brasil. Research, Society and Development, 9 (7), e232973866. https://doi.org/10.33448/rsd-v9i7.3866

Lima, P. W. (1998). Função hidrológica da mata ciliar. In. Barbosa, L.M. (coord.). In: Simpósio sobre Mata Ciliar, Campinas. Anais... Campinas: Fundação Cargill, p. 25-42.

Matos, A. M. do N., Mascarenhas Santos, M. do S. \& Súarez, Y. R. (2020). Pagamento por serviços ambientais como ferramenta de recuperação e conservação de zonas ripares. Research, Society and Development, 9(9), e788997752. https://doi.org/10.33448/rsd-v9i9.7752

Oliveira, J. B. \& Blamires, D. (2013). Aves do Campus do Instituto Federal de Educação em Iporá, Estado de Goiás. Seminário: Ciências Biológicas e da Saúde, 34(1), 45-54.

Pinheiro, C. U. B. (2016). Matas ciliares e conservação das nascentes dos rios Anil, Bacanga e Tibiri, na Ilha de São Luís, Maranhão. Revista Brasileira de Geografia Física, 9 (4), 1212-1222.

Peña, A. P., Tavares, D. de O., Jorge, R. F., Pires, R. A. P., Tavares, T. de O., Guimarães, T. V. de C. \& Ramalho, W. P. (2010). Estrutura e status de conservação das comunidades de vertebrados do Parque Estadual da Serra de Caldas Novas - PESCAN, Relatório Técnico, ONG PRÓ-TARTARUGA, Goiânia-GO.

Ribeiro, J. F. \& Walter, B. M. T. (2001). As matas de galeria no contexto do bioma Cerrado. In: Cerrado: caracterização e recuperação de matas de galeria. Platina, DF: Embrapa Cerrados.

Rodrigues, A. S. L., Malafaia, G. \& Castro, P. T. (2008). A. Avaliação ambiental de trechos de rios na região de Ouro Preto-MG através de um protocolo de avaliação rápida. Revista de Estudos Ambientais, Blumenau, 10(1), 74-83.

SAAE. (2009). Serviço Autônomo de Água e Esgoto. Três Pontas: 23 de dezembro de 2009. https://www.saaetpo.mg.gov.br/a brir_arquivo.aspx/Dignostico_completo_manancial_Custodinho_2009?cdLocal=2\&arquivo=\{BDEE4DEE-EEDC-8142-4BAE-5EB3EEDBC3CC $\}$.pdf.

Sousa, M. J. A., Gonçalves, M. F., Oliveira, J. D. \& Lopes, C. K. S. (2021). O índice de qualidade da água da sub-bacia do córrego Cacau, Portal da Amazônia Imperatriz -MA. Pesquisa, Sociedade e Desenvolvimento, 10 (2), e45510212631. https://doi.org/10.33448/rsd-v10i2.12631

Souza, D. I. et al. (2013). Manual de orientações para projetos de pesquisa. FESLSVC, 2013. http://www.liberato.com.br/sites/defa ult/files/manual_de_orientacoes_para_projetos_de_pesquisa.pdf .

Stanganini, F. N. \& Lollo, J. A. (2018). O crescimento da área urbana da cidade de São Carlos. URBE. Revista Brasileira de Gestão Urbana (Brazilian Journal of Urban Management), 10(Supl. 1), 118-128.

Tanago, M. G., Jalón, D. G., Lara, F. \& Garilleti, R. (2006). Índice de RQI para lavarolación de las ribeiras fluviales en el contexto de la directiva marco del agua. Ingeniería civil, 143, 1-12.

Vogel, H. F., Zawadzki, C. H., Metri, R. \& Valle, L. G. (2010). Levantamento preliminar e biologia da mastofauna da RPPN Ninho do Corvo no município de Prudentópolis - Paraná. SaBios - Revista de Saúde e Biologia, 5(2), 39-46. 